\title{
Have you made a vaccination error? Knowledge and perception of immunization errors in Catalonia.
}

Mirada $\mathrm{G}^{1}$, Urbiztondo $\mathrm{L}^{1}$, Borràs $\mathrm{E}^{1}$, Torres $\mathrm{J}^{1}$, Estany $\mathrm{P}^{2}$, Canals $\mathrm{M}^{2}$, Rabanal $\mathrm{M}^{3}$

${ }^{1}$ Agència de Salut Pública de Catalunya. ${ }^{2}$ Institut Català de la Salut. ${ }^{3}$ Direcció General d'Ordenació Professional i Regulació Sanitària

\section{Introduction}

Immunization is the procedure through which a person is vaccinated by a healthcare professional (HP), to induce specific immunity. Vaccination errors (VE) awareness may be important because of possible reduction in vaccine efficacy, presentation of adverse effects and confidence impairment in HPs and vaccines, according to patient safety perspective.

It is important to assess the scope of VE in order to plan HP training in order to reduce its impact.

\section{Goal}

To know the degree of error perception, perceived frequency, conditioning factors, level of knowledge about VE prevention and the actions to be taken in front of each one of them.

\section{Methods}

On-line survey carried out on HP in vaccination centers (VC) of 2 health regions of Catalonia.

\section{Vaccination errors. Has it ever happened?}

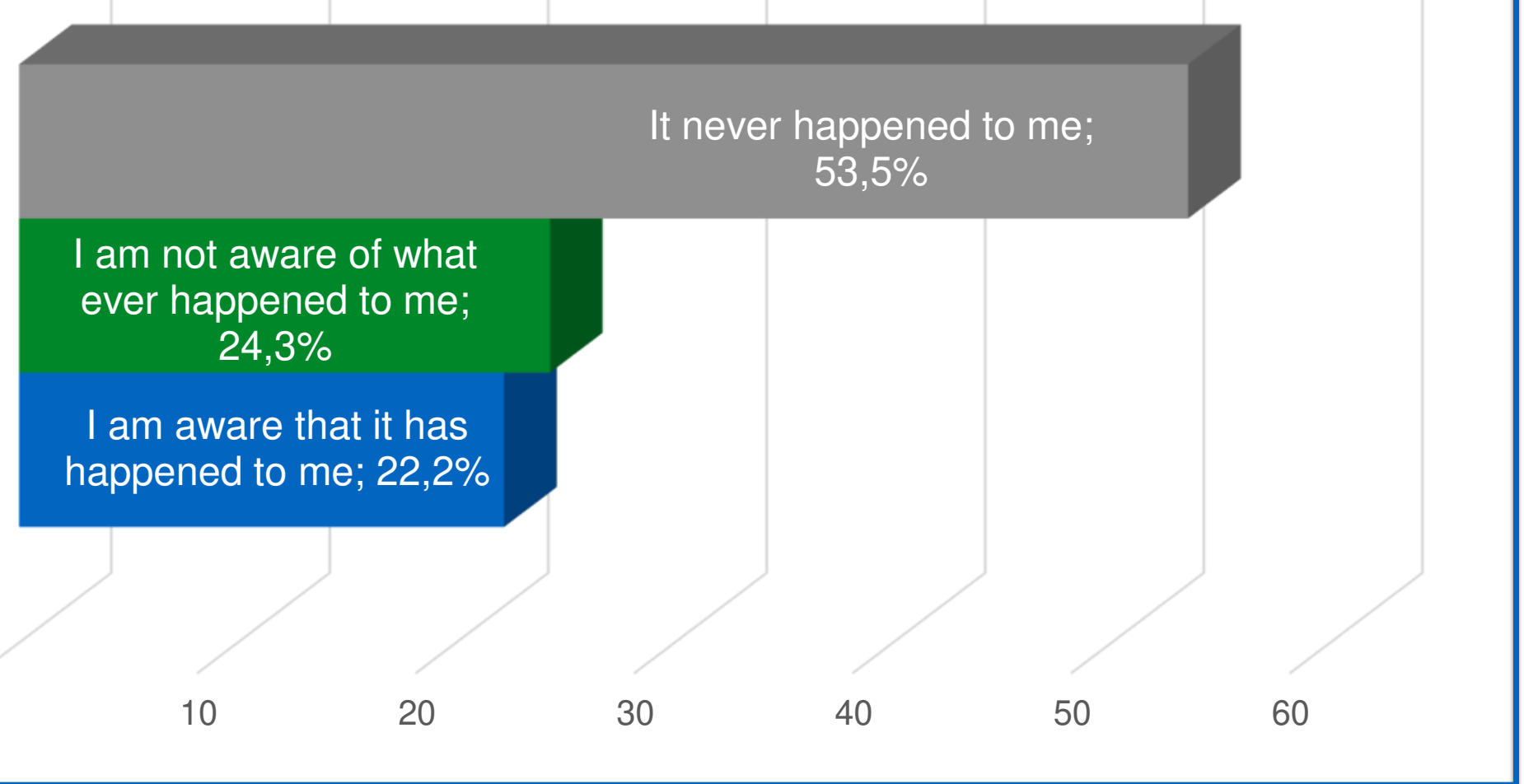

Results

- 740 surveys were sent and the response rate was $31 \%$ (232).

- $92.7 \%$ were responded by nurses.

- $52.6 \%$ had been working for over 20 years.

- Degree of perception of VE was $66.1 \%, 22.2 \%$ had personal perception it happened some time ago, while $84.5 \%$ believed it happened in the VC to other HP.

- The main reasons declared for VE were work overload, similar packagings and brand changes.

- $60 \%$ knew the procedure for postVE.

\section{Conclusion}

Majority of HP are aware of the fact that VE is committed. Errors occur because $\mathrm{HP}$ are not aware of the nature of VE and because there is no knowledge of an existing notification system for VE reporting. We believe that training and VE notification systems are necessary.

\section{Do you think that in your center are vaccinations errors?}



